\title{
PET-Guided Evaluation and Optimization of Internalized Antibody-Drug Conjugates Targeting Erythropoietin-Producing Hepatoma A2 Receptor
}

\author{
Orit Jacobson ${ }^{1}$, Qing $\mathrm{Li}^{2}$, Haojun Chen ${ }^{1}$, Gang $\mathrm{Niu}^{1}$, Dale O. Kiesewetter ${ }^{1},{\text { Lan } \mathrm{Xu}^{2} \text {, Kimberly } \text { Cook }^{2} \text {, Gengcheng Yang }}^{2}$, \\ William Dall'Acqua ${ }^{2}$, Ping Tsui ${ }^{2}$, Li Peng ${ }^{2}$, and Xiaoyuan Chen ${ }^{1}$ \\ ${ }^{1}$ Laboratory of Molecular Imaging and Nanomedicine, National Institute of Biomedical Imaging and Bioengineering, National \\ Institutes of Health, Bethesda, Maryland; and ${ }^{2}$ Department of Antibody Discovery \& Protein Engineering, MedImmune LLC, \\ Gaithersburg, Maryland
}

The erythropoietin-producing hepatoma $\mathrm{A} 2$ receptor (EphA2) is a tyrosine kinase overexpressed by tumor stroma and cancer cells. A high expression level of EphA2 predicts poor prognosis, correlating with disease progression and metastasis. Therefore, EphA2 is a relevant therapeutic target for human cancer. Antibodies, selectively bound to EphA2, can induce rapid receptor phosphorylation that results in antibody internalization and degradation. This internalization mechanism has been exploited with the development of antibody-drug conjugates (ADCs) for cancer chemotherapy. In this study, we used PET imaging to study the pharmacokinetics and tumor delivery of a panel of anti-EphA2 monoclonal antibodies (mAbs) with and without drug conjugates. Methods: A library of human anti-EphA2 mAbs were screened and evaluated for EphA2 internalization rate, binding affinity, epitope binding, and hydrophobicity. We chose 3 of these antibodies, denoted as $1 \mathrm{C} 1,3 \mathrm{~B} 10$, and $2 \mathrm{H} 7$, which recognize different epitopes, for further evaluation. ADCs were generated by S239C mutation to give a ratio of 2 drug molecules per antibody. Native mAbs and ADCs were characterized, after conjugation to a DFO chelator and ${ }^{89} \mathrm{Zr}$ radiolabeling, in assays including cell uptake, internalization, hydrophobicity, and in vivo imaging using PET. Results: All $3 \mathrm{mAbs}$ had high affinities for EphA2 but exhibited different internalization rates following the order of $1 \mathrm{C} 1>3 \mathrm{~B} 10>2 \mathrm{H} 7$. Internalization rate is only 1 factor that affects in vitro cell uptake and in vivo tumor accumulation. Interestingly, the hydrophobicity of the mAbs, which followed the order of $2 \mathrm{H} 7>1 \mathrm{C} 1>$ 3B10, had a strong correlation with in vivo tumor uptake measured by PET, with the least hydrophobic antibody, 3B10, showing the highest tumor uptake. ADC significantly reduced the in vivo uptake of all 3 mAbs. Conclusion: Tumor uptake of $\mathrm{mAb}$ is a complex process that is affected by multiple parameters, including internalization, hydrophobicity, and chemical modification. Our results suggest that the addition of drug molecules to mAb increases the clearance of the mAb presumably due to the increased hydrophobicity. Understanding the complexity of antibody-based tumor delivery may help improve ADC engineering for better tumor targeting and reduced side effects.

Received Feb. 23, 2017; revision accepted May 4, 2017

For correspondence or reprints contact either of the following:

Xiaoyuan Chen, Laboratory of Molecular Imaging and Nanomedicine (LOMIN), National Institute of Biomedical Imaging and Bioengineering (NIBIB), National Institutes of Health (NIH), 35A Convent Dr., GD937, Bethesda, MD 20892-3759.

E-mail: shawn.chen@nih.gov

Ping Tsui, Department of Antibody Discovery \& Protein Engineering, Medlmmune LLC, One Medimmune Way, Gaithersburg, MD 20878.

E-mail: tsuip@medimmune.com

Published online May 25, 2017.

COPYRIGHT (C 2017 by the Society of Nuclear Medicine and Molecular Imaging.
Key Words: antibody; antibody drug conjugate; EphA2; internalization; positron emission tomography (PET)

J Nucl Med 2017; 58:1838-1844

DOI: 10.2967/jnumed.117.192245

\section{$\mathbf{T}$}

he erythropoietin-producing hepatoma (Eph) receptor family is the largest among all receptor protein tyrosine kinases and consists of 2 major subclasses, EphrinA (EphA) and EphrinB (EphB), which are defined on the basis of their sequence homology and ligand specificities (1-3). Members of this family are believed to be involved in different developmental processes based on their expression patterns during embryogenesis (2). Eph receptor ligands, ephrins, are membrane bound and play a role in cell-cell interaction. EphA is anchored to the cell membrane and its binding to Eph receptor does not affect the cell that expresses the ligand, whereas EphB has a transmembrane domain and on binding to Eph receptor it induces a bidirectional signaling to both interacting cells $(2,4)$.

Numerous studies described the expression and regulation of Eph receptors or their ligands in tumor stroma and cancer cells (4-9). Eph receptor and ephrin expression levels are correlated with cancer pathogenesis such as progression, metastatic spread, and patient survival (4). In particular, Ephrin receptor A2 (EphA2) has low or negligible expression in normal epithelial tissues; however, its upregulation in cancer has been well established. Its expression was found on the cell surface of many human tumors and was linked to increased malignancy and a poor clinical prognosis (10-17). Consequently, EphA2, in particular, has become an attractive therapeutic target as well as a target for the delivery of drugs, toxins, or imaging agents to cancer tissue. Targeted delivery can be achieved using antibody-drug conjugates (ADCs) of chemotherapeutic drugs or toxins to EphA2-specific antibodies that, due to receptor-mediated internalization of the antibody, allow delivery of highly cytotoxic drug to the tumor cells $(18-20)$.

Jackson et al. reported in 2008 on the first in vitro and in vivo evaluation of specific and potent antitumor activity of ADCs targeting the EphA2. They conjugated the cell-impermeable cytotoxic drug monomethyl auristatin phenylalanine to the highly internalized anti-EphA2 monoclonal antibody (mAb) $1 \mathrm{C} 1$ and showed that this conjugate was cytotoxic to tumor cells expressing EphA2 (20). 1C1 was also labeled with ${ }^{64} \mathrm{Cu}$, after conjugation of the antibody with 
the chelating agent DOTA, and used for noninvasive PET of EphA2 levels in different tumor types (21). Recently, DS-8895a, an antiEphA2 antibody, was labeled with appropriate radionuclides for PET and SPECT and applied to quantitative assessment of EphA2 expression and saturation in tumor models (22).

In this article, we investigated the usefulness of PET imaging as a tool to measure in vivo delivery and pharmacokinetics of antibodies and their conjugates. We studied several biologic and chemical characteristics of ADCs that may affect the pharmacokinetics. Understanding the antibody's properties that affect tumor delivery, specifically in the Eph system, may help clarify its role and mechanisms in cancer development, progression, and metastasis and may improve anti-Eph therapy.

\section{MATERIALS AND METHODS}

\section{Cell Culture}

The PC3 human prostate cancer cell line was purchased from the American Type Culture Collection and grown as prescribed by the vendor.

\section{Human Monoclonal Anti-EphA2 Antibodies}

Human mAbs were identified from Dyax recombinant antibody phage library Fab310 (23). Briefly, the phage library was incubated with $2 \%$ milk and control human IgG to remove Fc binding phage before binding to the EphA2-coated immunotubes $(20 \mu \mathrm{g} / \mathrm{mL}$ in $0.1 \mathrm{M}$ sodium bicarbonate buffer [pH 9.6]). After a 2-h incubation, the immunotubes were washed with phosphate-buffered saline (PBS) plus $0.1 \%$ polysorbate (PBS-T). The bound phage was eluted with $1 \mathrm{~mL}$ of $100 \mathrm{mM}$ triethylamine (Sigma), neutralized with $0.5 \mathrm{~mL}$ of $1 \mathrm{M}$ Tris- $\mathrm{HCl}$ ( $\mathrm{pH} 7.5$ ), and used to infect log phase TG1 cells (Novagen). The resulting colonies were collected and infected with helper phage M13K07 (Invitrogen). The infected cells were cultured overnight in 2YT medium with carbenicillin (Sigma) and kanamycin at $30^{\circ} \mathrm{C}$ to generate high titer phage.

EphA2 binding phage was identified in enzyme-linked immunosorbent assay, and the sequence-unique clones were converted to fulllength human IgG1 as described previously (24). The antibodies were transiently expressed in HEK293 cells using the transfection reagent 293 fectin according to the manufacturer's instructions. The secreted antibody in culture supernatant was purified using a precast protein-A column (GE Healthcare). The antibody was eluted from the column with acidic buffer ( $\mathrm{pH} 3.0$ ), neutralized, and dialyzed against PBS. The concentration of the purified antibody was calculated from the solution's optical density at $280 \mathrm{~nm}$.

\section{EphA2 Enzyme-Linked Immunosorbent Assay}

Enzyme-linked immunosorbent assay plates (Costar) were coated with $10 \mu \mathrm{g} / \mathrm{mL}$ of EphA2-Fc. After being washed and blocked with 5\% milk for $1 \mathrm{~h}$ at room temperature, the phage was added to each well of the blocked plates. The plates were washed and incubated with antiM13-HRP antibody (GE Healthcare) for $1 \mathrm{~h}$ before detection with SureBlue TMB peroxidase substrate (KPL). The reaction was stopped with $50 \mu \mathrm{L}$ of $0.2 \mathrm{M} \mathrm{H}_{2} \mathrm{SO}_{4}$, and the enzyme-linked immunosorbent assay signal was read at $450 \mathrm{~nm}$.

\section{Binding Affinity Assays in PC3 Cells}

Binding assays were performed using flow cytometry (fluorescenceactivated cell sorting [FACS]) in a 96-well U-bottomed plate (Thermo Scientific). PC3 cells were trypsinized and resuspended in FACS buffer $(1 \times$ PBS $+2 \%$ fetal bovine serum $)$ to a concentration of $0.5 \times 10^{6}$ cells $/ \mathrm{mL}$. A $100-\mu \mathrm{L}$ aliquot of cell suspension was transferred into each well, washed with $150 \mu \mathrm{L}$ of FACS buffer, and centrifuged at 1,500 rpm for $5 \mathrm{~min}$. The resulting cell pellets were suspended in 1:4 serial dilutions of antibodies in FACS buffer in 8 concentrations ranging from $20 \mu \mathrm{g} / \mathrm{mL}$ to $1.22 \mathrm{ng} / \mathrm{mL}$. Cells were then incubated with the antibody for $2 \mathrm{~h}$ on ice. After $2 \mathrm{~h}$, cells were spun down at 1,200 rpm for $5 \mathrm{~min}$ and washed twice with $250 \mu \mathrm{L}$ of FACS buffer. After the second wash step, the resulting cell pellets were suspended with $150 \mu \mathrm{L}$ of 1:250 dilution of goat antihuman AlexaFluor 647 secondary antibody (Life Technologies). Cells were incubated with the secondary antibody on ice for $1 \mathrm{~h}$ and washed twice with FACS buffer. After the last centrifugation, the FACS buffer was removed from the plate, and $150 \mu \mathrm{L}$ of 4',6-diamidino-2-phenylindole ( $3 \mu \mathrm{M}$, Life Technologies) were added to the wells to determine cell viability. Stained cells were acquired using a BD LSRII flow cytometry system (BD Biosciences), and data from the LSRII were analyzed using the software FlowJo.

\section{Binding Affinity Assay Using Surface Plasmon Resonance (SPR)}

A ProteOn XPR36 instrument (Bio-Rad) was used to determine the kinetics of the antibodies to human EphA2. Standard amine coupling was used to immobilize EphA2-Fc $(6 \mu \mathrm{g} / \mathrm{mL}$ in $10 \mathrm{mM}$ sodium acetate buffer, $\mathrm{pH}$ 5.0) to the EDAC/Sulfo-NHS-activated surface of a GLC biosensor chip (Bio-Rad) at a density of approximately 60 resonance units according to the manufacturer's instructions. Antibodies were prepared in PBS-T and injected at $100 \mathrm{~mL} / \mathrm{min}$ for $60 \mathrm{~s}$ at serial 2-fold dilutions of antibodies at concentrations ranging from 5 to $500 \mathrm{nM}$ to ensure the range for correct fitting. The dissociation phase was followed for $900 \mathrm{~s}$. Surfaces were regenerated by injecting $5 \mathrm{mM}$ $\mathrm{HCl}$, for $30 \mathrm{~s}$. All sensorgram data were processed using ProteOn Manager 3.1 software (Bio-Rad) and fitted to a 1:1 interaction model.

\section{Epitope Binding Characterization}

Epitope binding was performed using a ProteOn XPR36 instrument as follows: EphA2-Fc was immobilized onto a GLC sensor chip at density level of 800 resonance units using amino coupling chemistry (as described above). For a given antibody pair, the first antibody at a concentration of $1 \mathrm{mM}$ in PBS-T was injected at $30 \mathrm{~mL} / \mathrm{min}$ for $150 \mathrm{~s}$ to the EphA2-immobilized surface. A mixture of this same antibody with the second antibody ( $1 \mathrm{mM}$ in PBS-T) was then passed over the same surface.

\section{ADC}

Tubulysin variant (AZ13599185) was conjugated to the antibody via maleimidocaproyl linker through the maleimide-thiol reaction $(25,26)$. The antibodies, with an engineered cysteine at the position 239 of the constant domain (S239C), were reduced using tris-(2carboxyethyl)-phosphine (Fisher), oxidized by dihydroxyascorbic acid (Sigma), and site-specifically conjugated with the maleimidocaproyl-functionalized tubulysin AZ13599185. The resulting ADC was purified using type II ceramic hydroxyapatite chromatography to remove macromolecular aggregates and free drug. Conjugation efficiency and the drug-antibody ratio were determined using ultraviolet- and mass spectrometry-based methods following standard procedures (25).

\section{Cytotoxicity Assay}

Cytotoxicity assays were performed using PC3 cells following the protocol recommended in the Cell Titer-Glo kit (Promega). Briefly, $2 \times 10^{3}$ cells in $80 \mu \mathrm{L}$ of RPMI plus $10 \%$ fetal bovine serum were added to the inner wells of white walled 96-well plates (Costar). The ADCs were diluted to a $5 \times$ stock $(25 \mu \mathrm{g} / \mathrm{mL})$ in RPMI plus $10 \%$ fetal bovine serum. Antibodies were then serially diluted 1:3 in RPMI plus $10 \%$ fetal bovine serum, and $20 \mu \mathrm{L}$ of this dilution were added to the cells in duplicate, resulting in a 12-point dose curve of ADC ranging from $5 \mu \mathrm{g} / \mathrm{mL}$ at the highest concentration to $8.5 \times 10^{-5} \mu \mathrm{g} / \mathrm{mL}$ at the lowest dilution. Isotype $\mathrm{ADC}$, cell only, and medium-only controls were also included. Plates were incubated at $37^{\circ} \mathrm{C}, 5 \% \mathrm{CO}_{2}$ for $96 \mathrm{~h}$. At the 
end of the incubation period, $100 \mu \mathrm{L}$ of the substrate solution (Promega) were added to each well. Luminescence was measured using an Envision Multilabel reader (Perkin Elmer). Data were analyzed and graphed using GraphPad Prism (GraphPad Software).

Hydrophobic Interaction Chromatography-

High-Performance Liquid Chromatography (HIC-HPLC)

HIC-HPLC was performed using a butyl-NPR column (4.6-mm inner diameter $\times 3.5 \mathrm{~cm}, 2.5 \mu \mathrm{m}$; Tosoh Bioscience), and $25 \mathrm{mM}$ Tris$\mathrm{HCl}, 1.5 \mathrm{M}\left(\mathrm{NH}_{4}\right)_{2} \mathrm{SO}_{4}, \mathrm{pH} 7.0$ (solvent A) and $25 \mathrm{mM}$ Tris- $\mathrm{HCl}, 5 \%$ isopropanol, $\mathrm{pH} 7.0$ (solvent B). Antibody or ADC $(50 \sim 100 \mu \mathrm{g}$; $100-\mu \mathrm{L}$ volume) was loaded and eluted at a flow rate of $0.8 \mathrm{~mL} / \mathrm{min}$ with a gradient of $5 \%$ B to $100 \%$ B over 13 min.

\section{Isoelectric Point (pl) Measurements}

The buffers of all antibody samples were exchanged into water, diluted, and mixed with analytic reagents so that the testing mixture contained $0.25 \mathrm{mg} / \mathrm{mL}$ of protein, $0.35 \%$ methylcellulose solution, $0.04 \%$ Pharmalyte (pH 3-10), 0.5\% pI marker 5.85, and $0.5 \% \mathrm{pI}$ marker 9.22. The protein charge heterogeneity analysis was performed on an iCE3 IEF analyzer (ProteinSimple) using a capillary cartridge with electrolytic tanks at each end. One tank was filled with acid (anolyte), and the other tank was filled with base (catholyte). The sample mixtures were loaded onto the iCE3 IEF analyzer and focused at $1,500 \mathrm{~V}$ for $1 \mathrm{~min}$, followed by $3,000 \mathrm{~V}$ for $5 \mathrm{~min}$. Analysis was done using Chrom Perfect iCE3 software and integrated for charge isoforms composition using Empower 2.0 software.

\section{Antibody-Chelator Conjugation to Desferrioxamine-p-SCN and ${ }^{89} \mathrm{Zr}$ Radiolabeling}

Desferrioxamine-p-SCN (Df) (Macrocyclics) conjugation and ${ }^{89} \mathrm{Zr}$ radiolabeling of $\mathrm{mAb}$ were done similarly to the literature procedure (27), using a 1:20 molar ratio (mAb:Df). Purification of the mAb was done on a PD10 column (GE Healthcare) using PBS as eluent. The concentration of the mAb solution was determined by Nano-drop (UV at 280) (Fisher Scientific). ${ }^{89} \mathrm{Zr}$ labeling was conducted using $200 \mu \mathrm{g}$ (1.5 nmol) of antibody in $200 \mu \mathrm{L}$ of phosphate buffer $(\mathrm{pH} 7.5)$ and $37-56 \mathrm{MBq}$ of ${ }^{89} \mathrm{Zr}$ oxalate at $37^{\circ} \mathrm{C}$ for $30 \mathrm{~min}$. Radiolabeled antibody was isolated using a PD-10 cartridge eluted with saline. Radiochemical purity was determined by radio-thin-layer chromatography (Bioscan) using iTLC plates (Fisher Scientific) and $0.1 \mathrm{M}$ citric acid pH 5 as a solvent $\left(R_{f}\right.$ of ${ }^{89} \mathrm{Zr}$ antibody, $\sim 0.1$; free ${ }^{89} \mathrm{Zr}, \sim 0.9$ ).

\section{Cell Uptake and Internalization}

PC 3 cells were seeded in 24-well plates at a density of $10^{5}$ cells/well $24 \mathrm{~h}$ before the assay. The medium was removed, and the cells were rinsed once with PBS. Then, $0.0185 \mathrm{MBq} /$ well of ${ }^{89} \mathrm{Zr}-1 \mathrm{C} 1,{ }^{89} \mathrm{Zr}-3 \mathrm{~B} 10$, and ${ }^{89} \mathrm{Zr}$ - $2 \mathrm{H} 7$ were added in $0.5 \mathrm{~mL}$ of serum-free medium. The cells were incubated at $37^{\circ} \mathrm{C}$ for $15,60,120$, and $240 \mathrm{~min}$. For cell uptake studies, at each indicated time point, the medium was removed, and cells were rinsed twice with $1 \mathrm{~mL}$ of PBS and lysed by addition of $0.2 \mathrm{~mL}$ of $0.1 \mathrm{M} \mathrm{NaOH}$. For internalization studies, after the removal of the medium at the indicated time point, the cells were incubated for $1 \mathrm{~min}$ with $0.5 \mathrm{~mL}$ of acid buffer ( $50 \mathrm{mM}$ Glycine, $100 \mathrm{mM} \mathrm{NaCl}, \mathrm{pH}$ 2.8). Then the acid buffer was removed, and the cells were washed twice with $1 \mathrm{~mL}$ of PBS, followed by addition of $0.1 \mathrm{M} \mathrm{NaOH}$. Cell lysate was collected, and the radioactivity was measured by a $\gamma$-counter. The cell uptake and internalization values were normalized to the amount of added radioactivity. Each experiment was done in triplicate.

\section{Evaluation of ${ }^{89} \mathrm{Zr}$-Labeled mAbs and ADCs In Vivo}

In vivo studies were conducted under an animal protocol approved by the National Institutes of Health Clinical Center Animal Care and Use Committee. Athymic nude mice (Envigo) were housed in an animal facility under pathogen-free conditions and inoculated with
$5 \times 10^{6}$ PC 3 cells on their right shoulders. The mice underwent smallanimal PET studies 21-25 d after inoculation (average tumor volume, $200-500 \mathrm{~cm}^{3}$ ). PET scans were obtained at $1,4,24,48$, and $72 \mathrm{~h}$ after injection, and their analysis was performed as previously described (27). Analysis of half-lives and area under the curve was done using GraphPad Prism software.

\section{Statistical Analysis}

Results are presented as mean \pm SD. Two-tailed paired and unpaired Student $t$ tests were used to determine differences within groups and between groups, respectively. $P$ values of less than 0.05 were considered statistically significant.

\section{RESULTS}

\section{Anti-EphA2 Antibody Binding and Internalization Characterizations}

A panel of human anti-EphA2 mAbs was screened for binding and internalization properties in vitro. Antibodies 1C1, 3B10, and $2 \mathrm{H} 7$ that recognized different binding epitopes, defined by noncompetitive binding to the recombinant EphA2 protein in the SPR experiment; had high-affinity binding to the recombinant as well as to the tumor cell-expressed EphA2; and varied in PC3 cell internalization rates were selected to further compare their tumor uptake capability in vivo using PET.

3B10 and 2H7 showed high-binding activities comparable to human EphA2-expressing PC3 cells by FACS measurement and to recombinant EphA2 protein by SPR measurement, indicating that intrinsic binding affinity (binding of 1 arm of the bivalent antibody to the antigen) and binding avidity (more than 1 arm of antibody binding to the antigen) play similar roles in the binding of these 2 antibodies (Table 1). On the other hand, binding activity of $1 \mathrm{C} 1$ to PC3 cells showed as much as 450-fold of higher than the SPR-measured dissociation constant to the recombinant EphA2, suggesting avidity significantly affects $1 \mathrm{C} 1$ binding to cell surface-expressed EphA2 (Table 1). Competition binding of the mAbs in the SPR experiment showed that the mAbs can bind concurrently to EphA2, indicating that they recognize different epitopes on the protein. Drug conjugation does not appear to affect binding of $1 \mathrm{C} 1$ and $3 \mathrm{~B} 10$ to the recombinant EphA2 (Table 1). Furthermore, 1C1-ADC and 3B10-ADC showed cytotoxicity effects comparable to PC3 cells, indicating well-preserved cell binding and internalization after the drug conjugation (Supplemental Fig. 1; supplemental materials are available at http://jnm.snmjournals.org). Binding properties of mAbs $1 \mathrm{C} 1,3 \mathrm{~B} 10$, and $2 \mathrm{H} 7$, as well as $1 \mathrm{C} 1-\mathrm{ADC}$ and 3B10-ADC, are summarized in Table 1.

\section{TABLE 1}

Binding Activities of mAbs and ADCs Determined Using Flow Cytometry and SPR

\begin{tabular}{lccc}
\hline \multicolumn{1}{c}{ Clone } & $\begin{array}{c}\mathrm{K}_{\mathrm{D}} \text { (PC3 cells) } \\
\mathrm{nM}\end{array}$ & $\begin{array}{c}\mathrm{K}_{\mathrm{D}} \text { (SPR, huEphA2) } \\
\mathrm{nM}\end{array}$ & $\begin{array}{c}\mathrm{pl} \\
\text { (measured) }\end{array}$ \\
\hline 1C1 & 0.1 & 45.9 & 9.13 \\
3B10 & 0.1 & 0.6 & 9.40 \\
2H7 & 1.0 & 3.2 & 8.55 \\
1C1-ADC & $\mathrm{ND}$ & 54.7 & 9.14 \\
3B10-ADC & $\mathrm{ND}$ & 1.1 & 9.44 \\
\hline
\end{tabular}

$\mathrm{KD}=$ dissociation constant. 


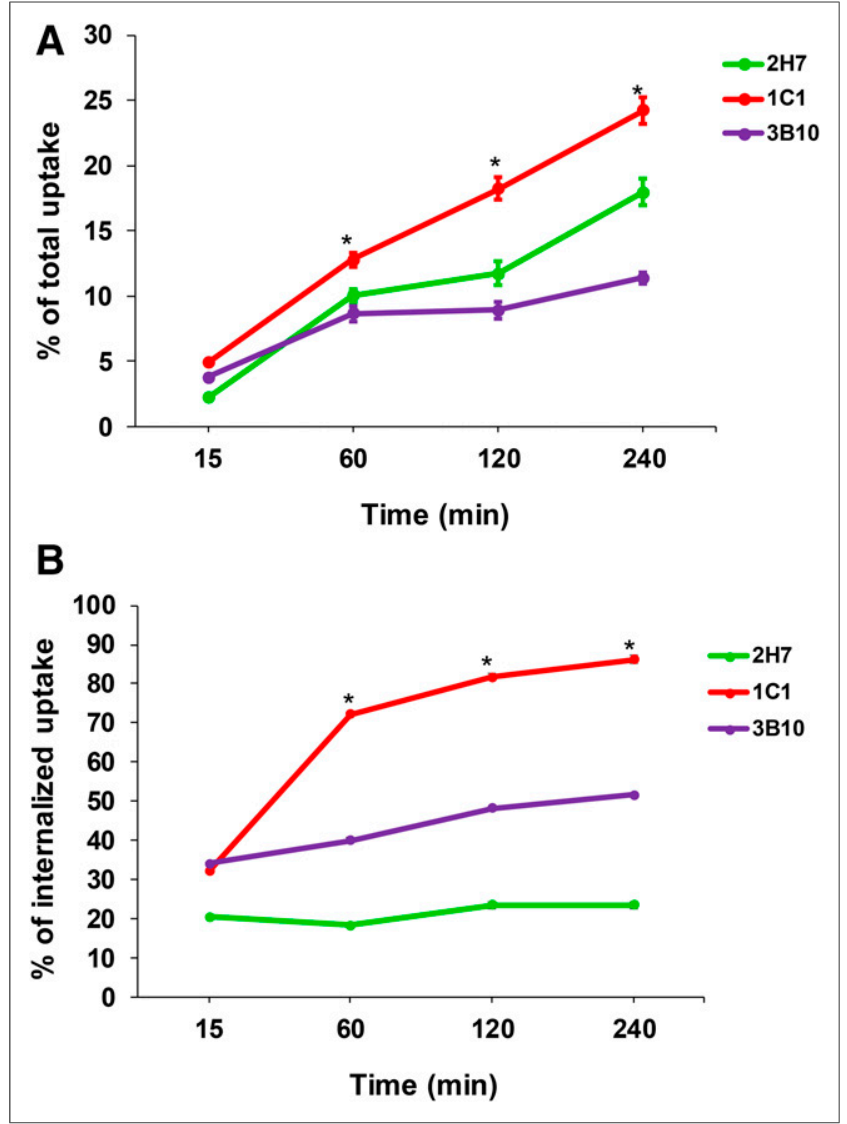

FIGURE 1. (A) Cell uptake (internalized and surface bound) of ${ }^{89} \mathrm{Zr}$ $1 \mathrm{C} 1$ (red), ${ }^{89} \mathrm{Zr}-3 \mathrm{~B} 10$ (purple), and ${ }^{89} \mathrm{Zr}-2 \mathrm{H} 7$ (green) in PC3 cells over time. (B) Percentage of internalization of each labeled $\mathrm{mAb}$ from total uptake presented in $\mathrm{A}$. ${ }^{*} P<0.01$ compared with $2 \mathrm{H} 7$ and $3 \mathrm{~B} 10$.

\section{Cellular Uptake and Internalization Assay}

The cellular uptake and internalization of ${ }^{89} \mathrm{Zr}-1 \mathrm{C} 1,{ }^{89} \mathrm{Zr}-3 \mathrm{~B} 10$, and ${ }^{89} \mathrm{Zr}-2 \mathrm{H} 7$ were evaluated in $\mathrm{PC} 3$ cells. Of the 3 antibodies, ${ }^{89} \mathrm{Zr}-1 \mathrm{C} 1 \mathrm{had}$ the highest uptake at all time points and the highest internalization fraction (5\% cellular uptake and $32 \%$ internalization fraction at $15 \mathrm{~min}$ to $22 \%$ cellular uptake and $81 \%$ internalization fraction at $2 \mathrm{~h}$, Fig. 1A). ${ }^{89} \mathrm{Zr}-3 \mathrm{~B} 10$ and ${ }^{89} \mathrm{Zr}-2 \mathrm{H} 7 \mathrm{had}$ significantly lower uptake and internalization fraction than ${ }^{89} \mathrm{Zr}$ 1C1 (Figs. 1A and 1B). ${ }^{89} \mathrm{Zr}-3 \mathrm{~B} 10$ had the lowest cellular uptake but had higher internalization fraction than ${ }^{89} \mathrm{Zr}-2 \mathrm{H} 7$ (increasing from $34 \%$ at $15 \mathrm{~min}$ to $52 \%$ at $4 \mathrm{~h}$ ). ${ }^{89} \mathrm{Zr}-2 \mathrm{H} 7$ did not have significant differences in its internalization fraction (Fig. 1B).

\section{Physical Properties of Native mAb and ADCs}

To determine hydrophobicity, 1C1, 3B10, and 2H7 mAbs as well as drug conjugates of 1C1-AZ13599185 and 3B10-AZ13599185 were injected into a hydrophobic interaction chromatography system, which separates proteins according to their polarity. The more hydrophobic antibody will have a longer retention time on this column. The elution profile showed that of the 3 antibodies, 3B10 was the most hydrophobic, followed by $1 \mathrm{C} 1$ and $2 \mathrm{H} 7$ (Fig. 2A). As drug conjugates, 3B10-AZ13599185 migrates faster than 1C1AZ13599185 (Fig. 2B). Notably, the overall retention time of the drug conjugates or ADCs are 0.5 min slower than the naked mAbs, indicating drug conjugation increased overall hydrophobicity.
We also measured the $\mathrm{pI}$ of the mAbs and ADCs by applying voltage that creates $\mathrm{pH}$ gradient, which separates and focuses the antibodies based on their pI. 1C1 and 3B10 had similar pIs of 9.13 and 9.40, respectively, whereas $2 \mathrm{H} 7$ had a lower value of 8.55 (Table 1). 1C1-ADC and 3B10-ADC had pIs similar to their parental antibodies, indicating drug conjugation has little if any effect on pI.

\section{Preparation of Radiolabeled Antibodies}

Conjugation of Df chelator was done on the free lysine residues of the antibody using a mole ratio of 20:1. The binding ability of the chelator-conjugated mAbs to PC3 cells remained similar to the nonconjugated ones (Supplemental Fig. 2). Radiolabeling with ${ }^{89} \mathrm{Zr}$-oxalate was accomplished in a 30-min reaction with complete incorporation of ${ }^{89} \mathrm{Zr}$ into the chelator, as determined by radiothin-layer chromatography. The ${ }^{89} \mathrm{Zr}$ antibodies were isolated from the reaction in $75 \% \pm 3 \%(n=4)$ radiochemical yields with specific activities of $46 \pm 2 \mathrm{MBq} / \mathrm{nmol}$ and radiochemical purities greater than $99 \%$.

\section{Evaluation of ${ }^{89} \mathrm{Zr}-\mathrm{mAb}$ and ${ }^{89} \mathrm{Zr}$-ADC In Vivo}

PET imaging provides a noninvasive method for evaluation of the biodistribution of the radionuclide as a function of time. The pharmacokinetics of the 3 labeled mAbs were first evaluated without the drug in PC3 xenografts using this technique. ${ }^{89} \mathrm{Zr}-1 \mathrm{C} 1$, ${ }^{89} \mathrm{Zr}-3 \mathrm{~B} 10$, and ${ }^{89} \mathrm{Zr}-2 \mathrm{H} 7$ were evaluated using $\mathrm{PET}$ scans in

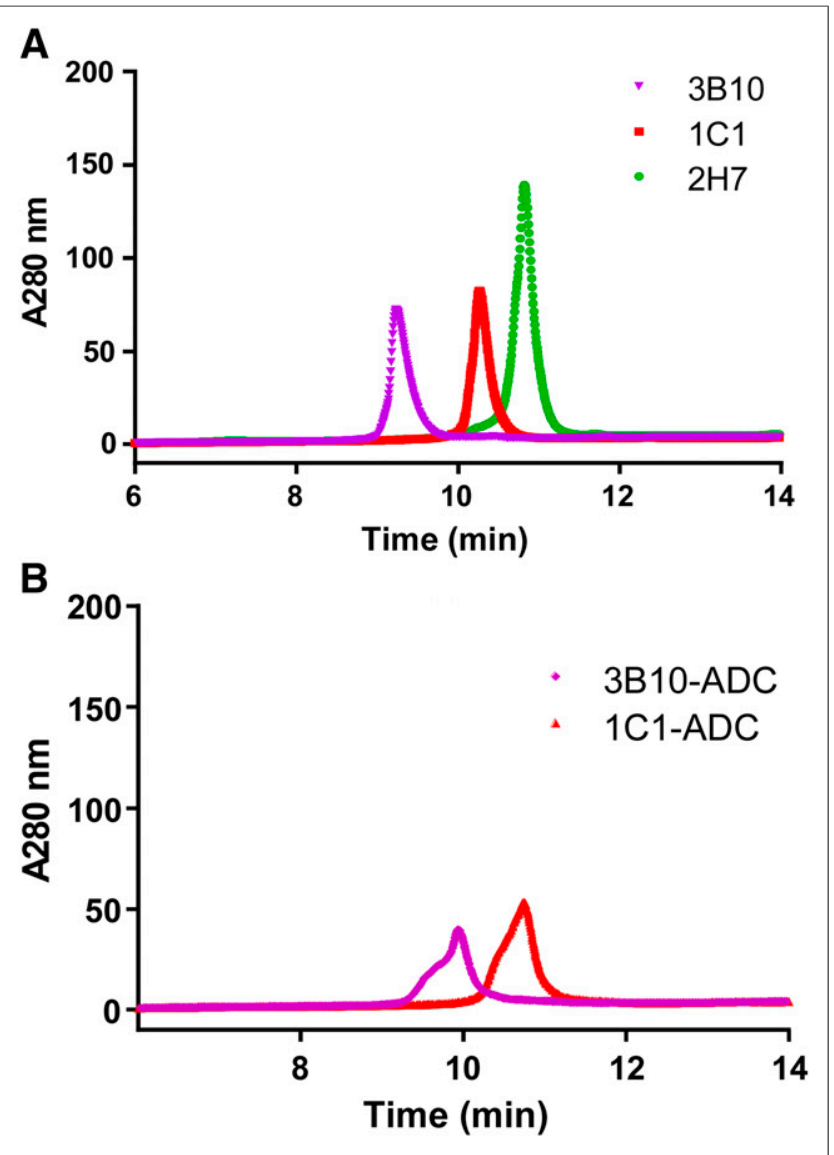

FIGURE 2. Hydrophobicity of naked mAbs and ADCs. (A) Hydrophobic interaction chromatography of native mAbs. (B) Hydrophobic interaction chromatography of 1C1-ADC and 3B10-ADC. 


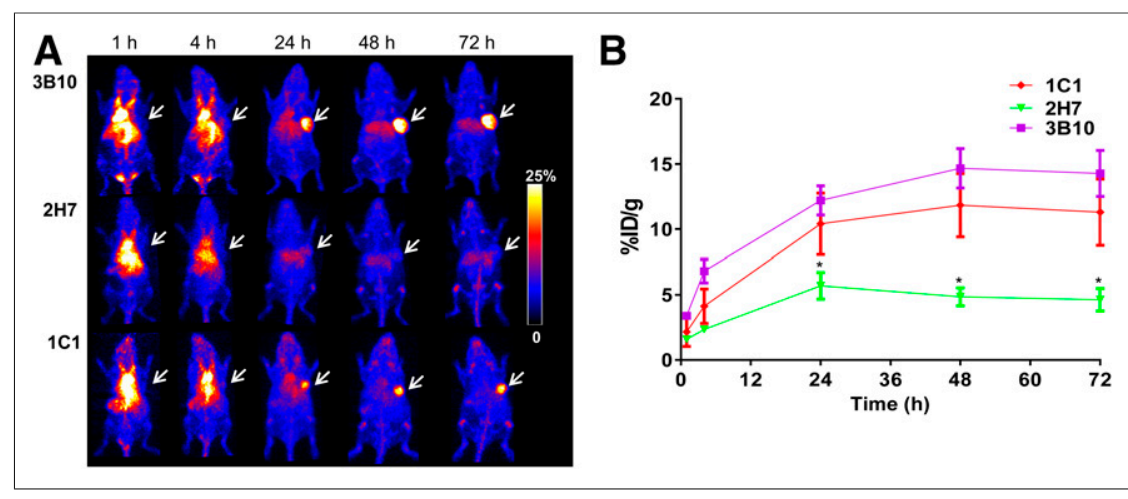

FIGURE 3. (A) Projection PET images of PC3 xenografts injected with $3.7 \mathrm{MBq}$ of ${ }^{89} \mathrm{Zr}-\mathrm{mAb}$ (3B10, upper row; 2H7, middle row; and 1C1, lower row) at different time points after injection. White arrows indicate tumor location. (B) Quantified results from PET images of tumor uptake of each labeled mAb. ${ }^{*} P<0.01$, compared with $1 \mathrm{C} 1$ and $3 \mathrm{~B} 10$.

xenograft models up to $72 \mathrm{~h}$ after injection (Fig. 3A). Because of the slow pharmacokinetics of antibodies and high blood circulation in vivo, the tumors were almost undetectable at 1 and $4 \mathrm{~h}$ after injection. The tumors were clearly visualized at the 24-h time point for ${ }^{89} \mathrm{Zr}-1 \mathrm{C} 1$ and ${ }^{89} \mathrm{Zr}-3 \mathrm{~B} 10$, with tumor uptake of $10.4 \pm$ 2.3 and $12.2 \pm 1.1$ percentage injected dose per gram, respectively, and clear tumor-to-background contrast (Fig. 3A). This uptake was slightly elevated at $48 \mathrm{~h}$ after injection. ${ }^{89} \mathrm{Zr}-3 \mathrm{~B} 10$ had a slightly higher tumor uptake than ${ }^{89} \mathrm{Zr}-1 \mathrm{Cl}$ at all time points examined (Fig. 3B). ${ }^{89} \mathrm{Zr}-2 \mathrm{H} 7$ had the lowest tumor uptake at all time points, with approximately $4.6-5$ percentage injected dose per gram at 24- and 72-h time points (Figs. 3A and 3B). Conjugation of tubulysin variant (AZ13599185) to $1 \mathrm{C} 1$ and $3 \mathrm{~B} 10$ resulted in a conjugation efficiency of greater than $97 \%$ and 2 drug molecules per antibody $(\mathrm{DAR}=2)$. A significant reduction in tumor uptake $(\sim 50 \%-60 \%$ reduction) was observed for both antibodies (Figs. 4A and 4B). Interestingly, blood uptake at $1 \mathrm{~h}$ after injection for ${ }^{89} \mathrm{Zr}-1 \mathrm{C} 1$ and ${ }^{89} \mathrm{Zr}-3 \mathrm{~B} 10$ was higher than their ADC counterparts, ${ }^{89} \mathrm{Zr}-1 \mathrm{C} 1-\mathrm{ADC}$ and ${ }^{89} \mathrm{Zr}-3 \mathrm{~B} 10-\mathrm{ADC}$ (Fig. 5A). Tumor-to-blood ratios of ${ }^{89} \mathrm{Zr}-1 \mathrm{C} 1$ and ${ }^{89} \mathrm{Zr}-3 \mathrm{~B} 10$ were higher than their ADCs at 24-, 48-, and 72-h time points, which correlates with their higher tumor uptake and similar blood uptake at these time points. No significant differences were observed for tumorto-muscle ratios (Fig. 5B). Pharmacokinetic analysis of both antibodies with and without the ADC shows that addition of drug conjugate reduced both blood half-life and area under the curve by approximately half, suggesting that the ADCs are cleared faster than the antibodies (Table 2). ${ }^{89} \mathrm{Zr}-1 \mathrm{C} 1$ and ${ }^{89} \mathrm{Zr}-3 \mathrm{~B} 10$ also had elevated liver uptake, perhaps due to increased hydrophobicity after drug conjugation (Fig. 5A).

\section{DISCUSSION}

EphA2 overexpression in multiple tumor and tumor stromal cells make it an attractive candidate for drug development and cancer therapeutics. One such therapy is blocking EphA2/Ephrin binding to inhibit tumor growth, migration, and invasiveness of aggressive cancers in animal models $(28,29)$. Moreover, binding to EphA2 can induce antibody internalization, which provides a method to deliver potent cytotoxic drug into cancer cells (30). This ADC approach has proven to be effective in inhibition of tumor growth and gives better results than the antibody without drug conjugate (20).

Drug conjugation can have profound effects on the pharmacokinetics, tissue distribution, metabolism, and pharmacology of the antibody, and therefore ADC should be separately evaluated in vivo (31). In vivo imaging of radiolabeled naked antibody and the ADC can provide valuable information concerning tumor accessibility affected by the drug conjugation. This is especially important for ADC development, because performance in vitro may not always predict in vivo properties due to complex in vivo factors affecting the drug activity and drug delivery.

In this study, we chose $3 \mathrm{mAbs}$ that bind the same target, EphA2, but display different characteristics such as epitope binding, internalization, $\mathrm{pI}$, and hydrophobicity. We explored the factors that affect the tumor uptake and pharmacokinetics of the mAbs and ADCs in vivo using quantitative PET imaging. The mAbs were labeled with a long-lived PET isotope, ${ }^{89} \mathrm{Zr}$ (half-life, $3.3 \mathrm{~d}$ ), to allow imaging over a long time frame. Radiolabeling was efficient when the chelator was conjugated onto the lysine residues. However, when site-specific labeling was attempted by coupling Df-maleimide onto 1 of the 2 free cysteine residues in the $\mathrm{mAb}$, the radiolabeling yields were significantly lower, perhaps due to the significantly lower specific activities. To get high specific activities along with reasonable uptake and internalization in cells, we evaluated the amount of the chelator needed for the conjugation and found 1:20 eq (mAb:Df chelator) provided the best results in cell assays. Therefore, we decided to maintain this ratio and the chelator for further in vivo evaluation of the native $\mathrm{mAb}$ and $\mathrm{ADC}$.

Intuitively, we thought that the antibody that possesses the highest internalization rate in vitro will have the highest tumor accumulation in vivo. Theoretically, due to receptor internalization and recycling, the antibody concentration in the blood will always be higher than the concentration bound to the cell surface, which will increase its binding to the cells and result in higher accumulation. Moreover, an internalized antibody is less susceptible to cleavage/ degradation, and if it is degraded inside the cell, the activity might be still retained in the cell. However, how an antibody
FIGURE 4. (A) Projection PET images of PC3 xenografts injected with $3.7 \mathrm{MBq}$ of ${ }^{89} \mathrm{Zr}-\mathrm{ADC}$ (1C1, upper panel, and 3B10, lower panel) at different time points after injection. White arrows indicate tumor location. (B) Quantified results of tumor uptake of ADC over time.

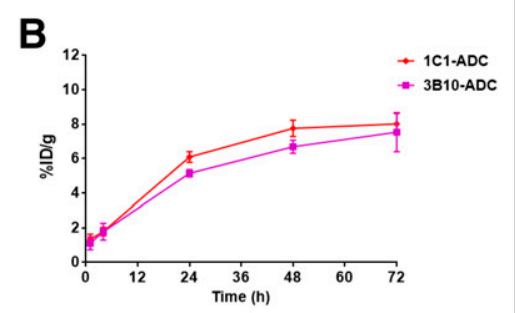




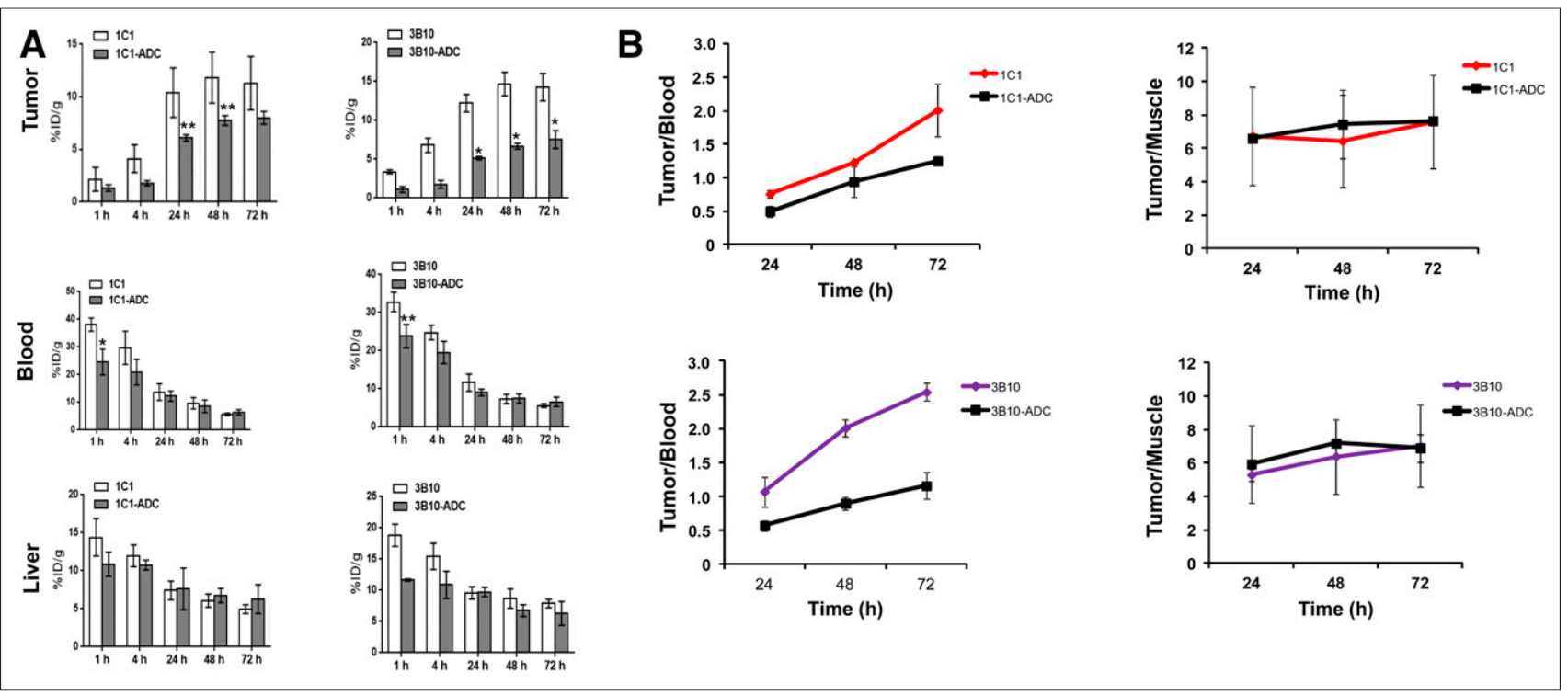

FIGURE 5. (A) Biodistribution of ${ }^{89} \mathrm{Zr}$-ADC in tumor, blood, and liver over time. (B) Tumor-to-blood and tumor-to-muscle ratios of antibodies vs. ADC over time. ${ }^{*} P<0.01,{ }^{\star *} P<0.05$ antibodies compared with their ADC counterparts.

performs in vivo is affected by complex factors, such as the rate at which the receptor is recycled, antibody/ADC clearance from the blood, and others. Interestingly, our experimental results with the $3 \mathrm{mAbs}, 1 \mathrm{C} 1,3 \mathrm{~B} 10$, and $2 \mathrm{H} 7$, which displayed different internalization fractions in vitro, did not show correlation to in vivo tumor uptake. 1C1, which internalized most efficiently in vitro, did not exhibit the highest tumor uptake in vivo; whereas 3B10, which had lower cell internalization, had the highest in vivo tumor uptake (Figs. 1B and 3). As expected, 2H7, which had almost no internalization, exhibited the lowest tumor uptake (Figs. 1B and 3). On the other hand, we found a correlation between hydrophobicity and $\mathrm{pI}$ of the mAb and the in vivo tumor uptake. 3B10, which was the least hydrophobic mAb, had the highest tumor uptake, and $2 \mathrm{H} 7$, which was the most hydrophobic mAb, exhibited the lowest tumor uptake (Figs. 2 and 3). The pI of all 3 mAbs was higher than the physiologic $\mathrm{pH}$ and they were positively charged in the serum (Table 1). $1 \mathrm{C} 1$ and 3B10 had similar pIs, which were higher than $2 \mathrm{H} 7$, therefore were more positively charged than $2 \mathrm{H} 7$ and might have had better interaction with the negatively charged cellular membrane, leading to favorable tumor uptake and internalization. We hypothesized that both hydrophobicity and $\mathrm{pI}$ contribute to tumor uptake and internalization in vivo; hence, we chose $1 \mathrm{C} 1$ and $3 \mathrm{~B} 10$ for $\mathrm{ADC}$ experiments.

Next, we evaluated the changes in pharmacokinetics and tumor uptake when a drug was conjugated to the mAbs. The drug used

TABLE 2

Pharmacokinetics Parameters of Antibodies In Vivo

\begin{tabular}{lcc}
\hline \multicolumn{1}{c}{ Clone } & $\begin{array}{c}\text { Blood } \\
\text { half-life }(\mathrm{h})\end{array}$ & $\begin{array}{c}\text { Area under the curve } \\
\text { (radioactivity-hour/mL) }\end{array}$ \\
\hline 1C1 & 14.5 & 699.2 \\
1C1-ADC & 10.3 & 438.7 \\
3B10 & 9.1 & 875.3 \\
3B10-ADC & 7.6 & 385.9 \\
\hline
\end{tabular}

for constructing ADC was a tubulysin variant, AZ13599185, which was originally developed by AstraZeneca/MedImmune to inhibit microtubule polymerization during mitosis and induce cell death $(25,26)$. Drug conjugation resulted in a different pharmacokinetics profile, tissue distribution, and significantly lower tumor uptake (Figs. 4 and 5). Consistently with the tumor uptake results observed with the parental antibodies, the more hydrophobic ADC showed lower accumulation in the tumor (Figs. 2B and 4). Moreover, increased hydrophobicity in vivo can also enhance clearance from the blood through the hepatobiliary route, contributing to lower tumor uptake.

Because the Df chelator was conjugated to the mAb through lysine residues, we conjugated AZ13599185 via the engineered cysteine's malemide functional group at position 293 of the antibody (27). Mass spectrometry analysis after the drug conjugation showed that each ADC contained 2 drug molecules (data not shown). Drug conjugation via a thio group of antibody was also used in several ADCs that are in clinical trials for several cancer targets $(32,33)$. However, Boswell et al. recently reported that that drug conjugation through cysteine thiols can compromise the interchain disulfide bonds, resulting in faster clearance of the ADC in vivo (31). For a given drug, the chemical conjugation (method, site, and stoichiometry) is crucial to the effectiveness of ADC in vivo (32). Several approaches can be used for conjugation of the drug onto the mAb, such as conjugation on the $\varepsilon$-amino terminus of lysine residues or the sulfhydryl portion of a reduced cysteine residue or tertiary amine functional group $(33,34)$. Future work should compare different methods to link the drug to the mAb and evaluate which method has smaller variations in antibody pharmacokinetics behaviors.

\section{CONCLUSION}

$\mathrm{ADC}$ is an excellent system to deliver drugs to specific tumor lesions; however, it is critical to keep in mind that the conjugation of drug to $\mathrm{mAb}$ can have a profound effect on the pharmacokinetics of the mAb. Our results suggest that less hydrophobicity and higher $\mathrm{pI}$ of ADC can enhance drug availability at target organ. Extensive 
research in this area might yield an optimal range for both hydrophobicity and $\mathrm{pI}$ that will help future design of ADC.

\section{DISCLOSURE}

No potential conflict of interest relevant to this article was reported.

\section{REFERENCES}

1. Hirai H, Maru Y, Hagiwara K, Nishida J, Takaku F. A novel putative tyrosine kinase receptor encoded by the eph gene. Science. 1987;238:1717-1720.

2. Gale NW, Holland SJ, Valenzuela DM, et al. Eph receptors and ligands comprise two major specificity subclasses and are reciprocally compartmentalized during embryogenesis. Neuron. 1996;17:9-19.

3. Holland SJ, Gale NW, Mbamalu G, Yancopoulos GD, Henkemeyer M, Pawson T. Bidirectional signalling through the EPH-family receptor Nuk and its transmembrane ligands. Nature. 1996;383:722-725.

4. Pasquale EB. Eph receptors and ephrins in cancer: bidirectional signalling and beyond. Nat Rev Cancer. 2010;10:165-180.

5. Pratt RL, Kinch MS. Ligand binding up-regulates EphA2 messenger RNA through the mitogen-activated protein/extracellular signal-regulated kinase pathway. Mol Cancer Res. 2003;1:1070-1076.

6. Walker-Daniels J, Hess AR, Hendrix MJ, Kinch MS. Differential regulation of EphA2 in normal and malignant cells. Am J Pathol. 2003;162:1037-1042.

7. Lu M, Miller KD, Gokmen-Polar Y, Jeng MH, Kinch MS. EphA 2 overexpression decreases estrogen dependence and tamoxifen sensitivity. Cancer Res. 2003;63: 3425-3429.

8. Kinch MS, Moore MB, Harpole DH Jr. Predictive value of the EphA2 receptor tyrosine kinase in lung cancer recurrence and survival. Clin Cancer Res. 2003; 9:613-618.

9. Kinch MS, Carles-Kinch K. Overexpression and functional alterations of the EphA2 tyrosine kinase in cancer. Clin Exp Metastasis. 2003;20:59-68.

10. Ireton RC, Chen J. EphA2 receptor tyrosine kinase as a promising target for cancer therapeutics. Curr Cancer Drug Targets. 2005;5:149-157.

11. Landen CN Jr, Chavez-Reyes A, Bucana C, et al. Therapeutic EphA2 gene targeting in vivo using neutral liposomal small interfering RNA delivery. Cancer Res. 2005;65:6910-6918.

12. Wykosky J, Debinski W. The EphA2 receptor and ephrinA1 ligand in solid tumors: function and therapeutic targeting. Mol Cancer Res. 2008;6:1795-1806.

13. Amato KR, Wang S, Tan L, et al. EPHA2 blockade overcomes acquired resistance to EGFR kinase inhibitors in lung cancer. Cancer Res. 2016;76:305-318.

14. Faoro L, Singleton PA, Cervantes GM, et al. EphA2 mutation in lung squamous cell carcinoma promotes increased cell survival, cell invasion, focal adhesions, and mammalian target of rapamycin activation. J Biol Chem. 2010;285:1857518585.

15. Brannan JM, Sen B, Saigal B, et al. EphA2 in the early pathogenesis and progression of non-small cell lung cancer. Cancer Prev Res (Phila). 2009;2:10391049 .
16. Brannan JM, Dong W, Prudkin L, et al. Expression of the receptor tyrosine kinase EphA2 is increased in smokers and predicts poor survival in non-small cell lung cancer. Clin Cancer Res. 2009;15:4423-4430.

17. Coffman KT, Hu M, Carles-Kinch K, et al. Differential EphA2 epitope display on normal versus malignant cells. Cancer Res. 2003;63:7907-7912.

18. Senter PD. Potent antibody drug conjugates for cancer therapy. Curr Opin Chem Biol. 2009;13:235-244.

19. Carter PJ, Senter PD. Antibody-drug conjugates for cancer therapy. Cancer J. 2008;14:154-169.

20. Jackson D, Gooya J, Mao S, et al. A human antibody-drug conjugate targeting EphA2 inhibits tumor growth in vivo. Cancer Res. 2008;68:9367-9374.

21. Cai W, Ebrahimnejad A, Chen K, et al. Quantitative radioimmunoPET imaging of EphA2 in tumor-bearing mice. Eur J Nucl Med Mol Imaging. 2007;34:20242036.

22. Burvenich IJ, Parakh S, Gan HK, et al. Molecular imaging and quantitation of EphA2 expression in xenograft models with ${ }^{89} \mathrm{Zr}-\mathrm{DS}-8895 \mathrm{a} . \mathrm{J}$ Nucl Med. 2016;57:974-980.

23. Hoet RM, Cohen EH, Kent RB, et al. Generation of high-affinity human antibodies by combining donor-derived and synthetic complementarity-determiningregion diversity. Nat Biotechnol. 2005;23:344-348.

24. Jostock T, Vanhove M, Brepoels E, et al. Rapid generation of functional human IgG antibodies derived from Fab-on-phage display libraries. J Immunol Methods. 2004;289:65-80.

25. Christie RJ, Fleming R, Bezabeh B, et al. Stabilization of cysteine-linked antibody drug conjugates with $\mathrm{N}$-aryl maleimides. J Controlled Release. 2015;220: $660-670$.

26. Thompson P, Fleming R, Bezabeh B, et al. Rational design, biophysical and biological characterization of site-specific antibody-tubulysin conjugates with improved stability, efficacy and pharmacokinetics. J Controlled Release. 2016; 236:100-116.

27. Jacobson O, Zhu L, Niu G, et al. MicroPET imaging of integrin alphavbeta 3 expressing tumors using ${ }^{89} \mathrm{Zr}$-RGD peptides. Mol Imaging Biol. 2011;13:12241233.

28. Zeng G, Hu Z, Kinch MS, et al. High-level expression of EphA2 receptor tyrosine kinase in prostatic intraepithelial neoplasia. Am J Pathol. 2003;163:2271-2276.

29. Tandon M, Vemula SV, Mittal SK. Emerging strategies for EphA2 receptor targeting for cancer therapeutics. Expert Opin Ther Targets. 2011;15:31-51.

30. Li JY, Perry SR, Muniz-Medina V, et al. A biparatopic HER2-targeting antibodydrug conjugate induces tumor regression in primary models refractory to or ineligible for HER2-targeted therapy. Cancer Cell. 2016;29:117-129.

31. Boswell CA, Mundo EE, Zhang C, et al. Impact of drug conjugation on pharmacokinetics and tissue distribution of anti-STEAP1 antibody-drug conjugates in rats. Bioconjug Chem. 2011;22:1994-2004.

32. Drachman JG, Senter PD. Antibody-drug conjugates: the chemistry behind empowering antibodies to fight cancer. Hematology Am Soc Hematol Educ Program. 2013;2013:306-310.

33. Sievers EL, Senter PD. Antibody-drug conjugates in cancer therapy. Annu Rev Med. 2013;64:15-29.

34. Burke PJ, Hamilton JZ, Pires TA, et al. Development of novel quaternary ammonium linkers for antibody-drug conjugates. Mol Cancer Ther. 2016;15:938945. 